\title{
Quatre poèmes
}

\section{Muepu Muamba}

\section{OpenEdition \\ Journals}

Édition électronique

URL : https://journals.openedition.org/coma/5972

DOI : $10.4000 /$ coma.5972

ISSN : 2275-1742

\section{Éditeur}

Institut des textes \& manuscrits modernes (ITEM)

\section{Référence électronique}

Muepu Muamba, «Quatre poèmes », Continents manuscrits [En ligne], 15 | 2020, mis en ligne le 15 octobre 2020, consulté le 13 janvier 2023. URL : http://journals.openedition.org/coma/5972 ; DOI : https://doi.org/10.4000/coma.5972

Ce document a été généré automatiquement le 13 janvier 2023.

\section{(c) ()) (9)}

Creative Commons - Attribution - Pas d'Utilisation Commerciale - Pas de Modification 4.0 International - CC BY-NC-ND 4.0

https://creativecommons.org/licenses/by-nc-nd/4.0/ 


\section{Quatre poèmes}

\section{Muepu Muamba}

\section{NOTE DE L'ÉDITEUR}

«Venu à l'écriture en contrebande, par effraction, pour m'installer dans l'irrévérence et l'insoumission, mon but n'a jamais été de créer la beauté, mais plutôt d'ajouter ma voix aux espaces de résistance qui, à travers notre planète, disent non à l'intolérable. » Ainsi s'exprimait Muepu Muamba en 2016 sur le site parisglobalforum.org. Nous reproduisons ici quatre de ses poèmes inédits.

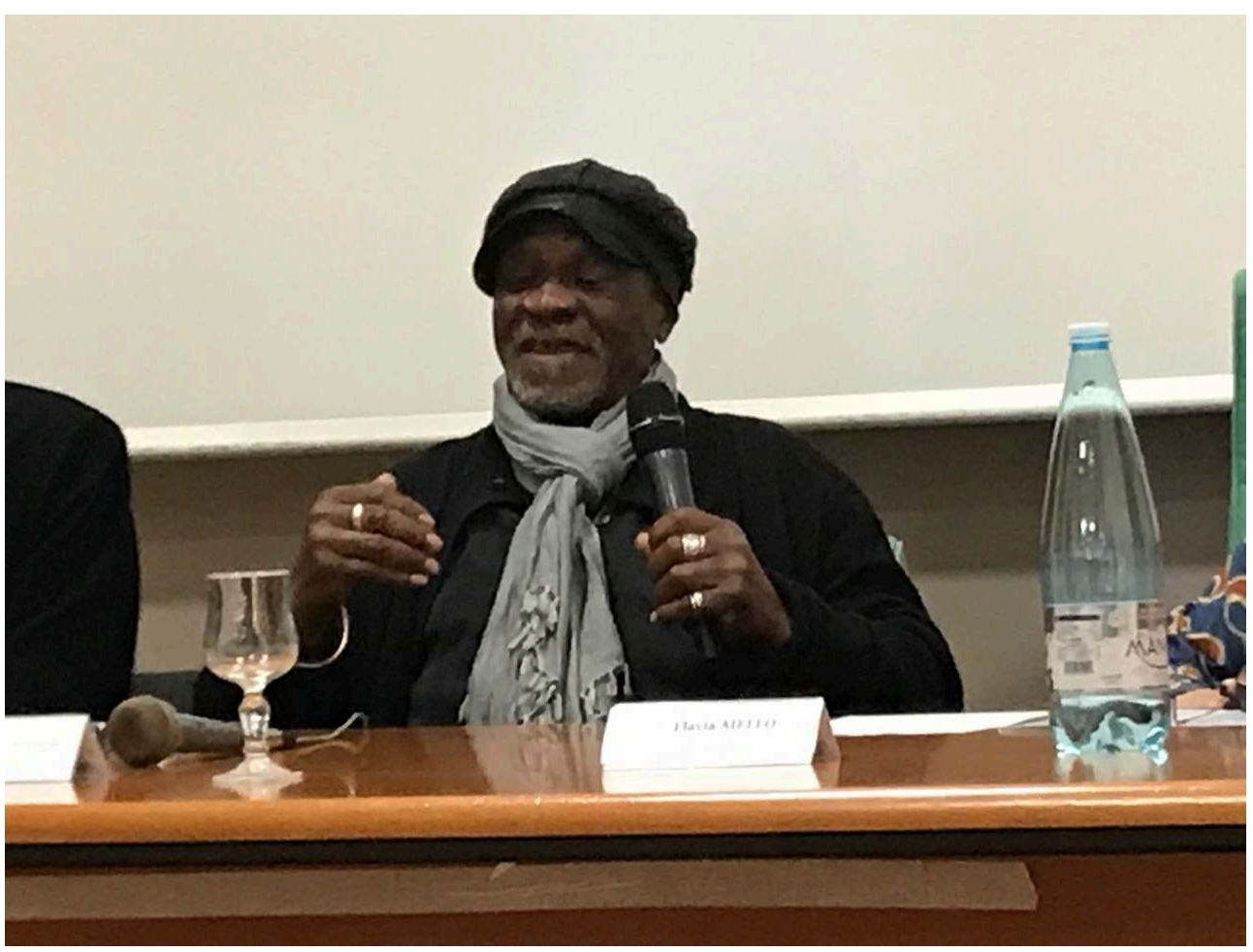




\section{Capoeira de marronage}

Chênes à trois œils

maîtres de l'impatience destructive du feu votre ombre lobée aux racines d'aïeux de profondeur de temps immémoriaux se penche sur la muraille d'entre hier et le jour qui naît de l'âpre suc de nos pourquoi chargée d'horreurs ainsi la mort torche d'or aux doigts nous déboise le demain de tendresse putative Ils sont débout encore toujours au rendez-vous de la colère généreuse telle l'attente du soir descelle les rives de songe sans âge

fûts altiers les rires d'insolence ancienne parent vos paupières de minuit étincelant dont les souvenirs du cri vagabond qui déchire les siècles des heures maudites se répercutent votre giron qui se donne au souffle oiseux du boréal ensanglanté infini de pleurs Tournez donc vos visages d'un rayon sublime vers nous les écumes déchiquetées qui avez aussi appris à dépenailler la terre comme les côtes déroutées de mers bohèmes les fouets dont les crimes se gravent sur la peau fragile de lunes vos lunes celles de vous-mêmes agissez un pas de danse triptyque danse du torrent épris des lèvres sensuelles leurs caresses impénitentes de mers du sud Capoera danse rebelle où le refus de courber l'échine feule de fierté regimbe la vieille mémoire dont vous possédez encore le secret Nous sommes l'aujourd'hui et le demain dont la main tendue s'effondre l'homme hale de taudis écorchant dans la tête ils nous disent encore une fois taisez-vous les mots égorgent coupent les tendons des étoiles 
à travers les noyades sépulcrales

qui fêlent l'espérance hérissée

2 C'est encore vous qui avez la parole sacrée

Vous l'Ancien

sur la Palissade du serment

cercle concentrique d'initiatique verset

la nôtre

présente et petite parole de salive étouffée

parole corrompue qui nous ronge les testicules

voués aux tables d'ignominies

il faut nous purifier à grandes eaux

primaires

il faut nous lessiver transmuer à l'orage des ondées sauvages aux extrémités fatales

On nous annonce que l'homme n'est plus l'homme

Il a étendu ses inoculations jusqu'à cloner Dieu

que les femmes sans face sans bourgeons

sans triangle herbeux de désir insondé

nous attendent aux déchirements

femmes glamours sans espace de sens

étroites de milles menottes

leur vaste sexe de fer barbelé tendu d'effigies

argentées pour jouir les banques centrales

femmes sans archives consubstantielles du temps

La Mort lente nous défeuille

Vous qui savez la voix primordiale du mystère

absolu de l'abyssal

la voix de l'eau

la voix de l'air

la voix maternelle de la terre

la voix virile $\mathrm{du}$ feu

entendez-vous encore ce que dire veut dire

comprenez-vous la Parole multiple de l'ÊTRE

venez donc guérir nos mains muettes

et sourdes

pour remonter le chemin de larmes

et du doute qui décime

venez nous réapprendre le mot limpide de

l'homme en vertu de la vie unifiée

l'éclat émouvant de la pierre vive habitée de rêves

à pied de la parole ardente

par-dessus vos épaules d'arbres stellaires

Capoeira danse de caïmans divins

quand la terre en ses saisons de l'amour se meut

féconde de plurielle senteurs

Alors nous redeviendrons des hommes

portés par nos songes insensés

au rythme de la démesure 
par delà les fardeaux de larmes et de deuil éparpillés

indices de tessons empoisonnés qui blessèrent

jadis votre aïeule de verdure

malgré ces boulets d'échappement qui nous

encombrent la mémoire

On nous impose de nous agenouiller au pied

putride de boussole équarrie d'infirmités

Mais vous vous étés enduits de la chaux de cette

mémoire

incantatoire de Blessure

Viens l'Ancien

Nous réenseigner le mot vigoureux de l'être

parole ardente

qui ne se dédit jamais.

3 Avant Propos

L'Âme est une immensité énigmatique qui nous raconte l'unisson des harmoniques de l'univers parce que notre corps est une petitesse aux dimensions du gérondif vaniteux mémoire fluide de l'innommé. Le corps habite l'âme pour s'éprendre aux mille secrets qui créent l'Être.

(Francfort-sur le-Main, le 10.01.2001)

\section{Mes Cinq Principes de Vie}

Ô Toujours. Luisant. Nomade. Incorrigible. Habitant de crêtes du vent rageur de l'esprit. Toujours en mitoyenneté permanente avec la brûlure de l'Incertain. Toujours en mitoyenneté avec. La.Parole. Ardente. Du. Doute. De crins hallucinés du soleil. DESOBÉIR. Absolument.

Si. Cela. Est. Nécessaire. Pulsation. Indéracinable. De. La. Dignité. De. La. Vie. L'ouvrir au coup d'ailes ingouvernés. De l'imprévisible avenir. La tendresse tourmentée de l'originelle gentiane.

Contre Mammon et ses grands prêtres psychopathes. Et. Drone. Comme. Un. Nouvel. Humanisme.

J'ai désobéi à mes parents Si c'était vraiment nécessaire perlé de désobéissance aux dieux Si c'était nécessaire au creux de la discourtoisie caillassé la loi Si c'était nécessaire J'ai disconvenu à mon héritage ancestral me suis à tâtons ensemencé ailleurs Si cela était nécessaire défié les choses lues. Fabriques multinationales 
de la pensée.

Cela est nécessaire.

Séditieux à moi-même

si c'était vraiment nécessaire.

Mais

Je n'ai jamais trahi ma conscience

cela n'était pas nécessaire

Mais

jamais soudoyé la vigilance de la vie

cela n'était pas vraiment nécessaire.

J'ai beaucoup aimé

Avec. Respect. Passion.

Cela est toujours vraiment nécessaire.

Aimer. Respecter.

Les femmes. Les hommes.

Concrets ;

Premier droit de l'homme.

Cela. Est. Constant. Généreusement.

Nécessaire.

Fondement. Minimum. Du temps. Intensité.

Spirituelle. De. La. Survie. De. Tout. Être.

Vivant. Mobile. Immobile.

Cela est vitalement nécessaire.

J'ai défié l'anomie de toutes les tyrannies de

supériorité et d'argent. Centres de rétention de la dignité.

Cela est toujours nécessaire

en amont de désobéissance á toutes les hiérarchies

factices. Que. Imposent. Le. Escroquerie.

De. L'esprit. Produits. Offshores. Financérisés.

Cela. Est. Vraiment. Nécessaire ;

Contre. A. Le. Injustice

vieille vicaire du pouvoir

cela est toujours nécessaire ;

A. Contre. Impunité mode d'emploi.

La vérité n'étant plus qu'expression de la force.

Cela est vertement nécessaire.

J'ai désobéi à ce cannibale monstrueux.

Insatiable

cela est vraiment éternel nécessaire.

Si longtemps que l'homme se travestit

en l'HOMME ;

Effréné. Fripé. Véreux.

D’ambitions. De. Puissance. De. Domination.

Cela est vraiment nécessaire.

Installé au creux de désobéissance à la vente aux enchères

de la vie décharnée. Bankarisée. A. Durée. Temporaire.

Cela est toujours vraiment nécessaire.

Mais je n'ai jamais déserté les mains créatrices de 
la terre vive. Feuillée envoûtée des ciels de long Désir ses harmoniques érotiques

cela n'était pas nécessaire.

J'ai déguerpi à toutes les esthétiques totalitaires cela est toujours vraiment nécessaire

A. Contre. Leurs razzias des âmes pour les privatiser. Les transformer.

En produits de consommation courante cela est toujours nécessaire affronté sans courber l'échine les regards d'abaissement. D'humiliation des êtres humains. Cela est toujours vigoureusement nécessaire. J'aime des mots qui étreignent les Rues. Comme. De rêves indociles. En dansant de délire.

Cela est nécessaire. De. Semence.

Qui se tissent des bourgeons des racines secrètes aux frémissements; d'Arbres. Paroles vives qui fleurissent. Cela est vraiment nécessaire aux estuaires insoupçonnées traînant plusieurs langues de leurs besaces cela est nécessaire.

Jamais personne n'effacera le sourire de mon visage ; En poussière encanaillée des étoiles cela est vivement nécessaire ; Mais jamais personne n'extirpera le rire Séditieux d'autres musiques d'autres frontières de ma fière gorge déployée cela est vraiment nécessaire. Vital. Ce devoir. Inaliénable. De. Désobéir.

Si. Cela. Est. Nécessaire.

Te voilà. ô jeune marron. De l'alizé. Prégnant. Déjà bousculé à l'équerre du doute d'impossibles incompromis. Surgi du bois sacré. Transmué de passage initiatique harnaché. Au creux de souvenirs. Récade d'honneur à la main. Ces mots sont pour toi. Absolument. Désobéir est le message inscrit aux croisés des lignes de tes pieds. Ils t'emportent au loin du monde ; Tu sais que tu es plus vieux que ton âge. Tu es plus ancien de plusieurs espérances. Tu es plus Ancien d'énigmatiques désirs.

Marche. Marche donc. Front haut. Et fier. Que ta parole Ardente. Assermentée. Pourfende A. Contre.

Robotisation. Non être. Homme-drone. Lynchage. Médiatique. Malversation. Maffieuse. De la pensée. Anorexie. De l'esprit. 
Sénescence. Dérythmie. De la vie.

Cela. Est. Ultime. Toujours. Vraiment. Nécessaire.

Pour que les escrocs cyniques n'écrivent pas de belles

oraisons funèbres sur nos tombes.

\section{Bêtise somptueuse}

$7 \quad$ Qu'il ne demeure point

une pierre sur une pierre

étau aux empruntes de bêtise monstrueuse

rendre l'âme décharnée

désunie de toute densité au vide violé

sans câlineries

Sarajevo

Les lettres sont endossement des horreurs

l'abjection s'y est lovée

et accrue aux contours des mains immondes

comme l'insoutenable

relief d'absurdité

Tu as posé déchiqueté l'écho du rythme

de séduction qui s'accumule

Quel homme avais-tu aimé

s'habillait-t-il d'une telle figure

de ruines féroces

Est-ce là la beauté du courage

le courage est-il l'amant impitoyable de la haine

et de la cruauté

qu'il ne demeure point

une tendresse sur une tendresse

vénéneuse prosopopée d'une épopée

odieuse

Je ne pleure jamais les pierres mortes

les pierres sèches ne connaissent pas

la primordiale

danse d'apprivoisement

même si l'on peut coucher une pierre

déracinée

sur une pierre

déracinée

Sarajevo

Mais

la magie d'une concupiscence

concentrique

de tes paumes en vagues velouteuses

qui rêvaient de réinventer les hommes 


\author{
à la dignité fraternelle \\ s'inonde-t-elle encore de la chaleur \\ hallucinante \\ de l'érection frémissante du semis de l'amitié \\ à l'orée d'aubes originales \\ Sarajevo \\ Le nom est une poubelle \\ de sang \\ où chaque frère paie chaque frère \\ comme tribut \\ à la joyeuse barbarie \\ La mort aux encoignures des rues \\ suppurantes \\ traque avec rage la vie si jobarde \\ et les caresses ne se faufilent les nids \\ de ta peau endurcie \\ et capitonnée de résonance spectrale \\ Quelles fleurs d'obscénités \\ offres-tu à l'innocence meurtrie \\ des enfants \\ bien sûr \\ Sarajevo \\ L'enfance déjà est partout noyée \\ dans la délinquance jouisseuse \\ des adultes \\ que des mots ont perdu toute \\ authenticité \\ toute tension de respect \\ ruisselants en lambeaux d'une marée \\ putride \\ et étincelante de pouvoir \\ Ils ne sont plus enflés \\ que de déchirure \\ que de pestilence. \\ (Francfort-sur-le-Main, le 06.04.1993)
}

\title{
Anorexie de la pensée
}

9 Non. Ils sont tous à l'affût mais je ne pleurerai pas mon

pays ils attendent dans tous les égouts du monde

que je m'apitoie sur moi-même pour se masturber

Je ne donnerai une occasion de jouissance

à l'armée de brutes le rire est terroriste ont-ils décrété

chorégraphie de l'horreur nous y sommes

plongés depuis tant de siècles et nous en sommes

débordés d'amputation une irruption ininterrompue et je

refuse de suivre le sentier que les vautour me tracent dans la 
flaque bourbeuse je revendique une autre façon d'habiter le monde Ils me veulent l'angoissé de la route les oubliettes de l'être je suis un muntu nanti de si vieilles plurielles paroles j'avais tant d'autres choses serties d'étrangetés jubilatoires en tête dont je connais aucune profondeur né hors toutes les croyances toujours en danse de langues en route cailloutée vers moi-même et les dieux étiquetés m'embêtent parce qu'ils sont génétiquement modifiés et sont dans des laboratoires stérilisés en transhumance de l'horreur pour le démantèlement de mots qui sont en nous et forgeant le souffle vitale de circulation de nous-mêmes en fleuraison avec l'univers ils veulent me cloner encore de violence divine certes je ne suis innocent de rien toujours décalé dans le temps Non je ne lamenterai pas mon pays je n'offrirai pas les masturbations aux salauds.

(Francfort-sur-le-Main, 02.01.2017)

\section{INDEX}

Mots-clés : poésie, littérature congolaise

\section{AUTEUR}

\section{MUEPU MUAMBA}

Poète (Devoir d'ingérence, Brazzaville-Heidelberg, Éditions Bantoues-P. Kivouvou Verlag, 1988), écrivain et journaliste, critique littéraire, directeur littéraire aux éditions Presses Africaines à Kinshasa, Muepu MUAMBA est né en 1946 en RDC. Il vit en exil depuis 1979, d'abord en Afrique, puis à Paris, actuellement à Francfort-sur-le-Main. 